folk/ed. Derg, 2021; 27(1):119-134

DOI: $10.22559 /$ folklor.1333

Research Article / Araştırma Makalesi

\title{
Kültürün Kökenlerinde Dayı Hukuku
}

\author{
Uncle Law in the Origins of Culture
}

\section{Berat Samet Kahraman*}

Öz

İnsan, bulunduğu kültürel yapı içinde aidiyet hissine ve köken bilincine sahip olmak ister. Akraba ilişkileri bu çerçevede önemli rol oynar. Özellikle ilkel toplumlarda dayının sahip olduğu ayrıcalıklı konumu ve koruyucu yapısı, diğer akraba ilişkilerinden farklıdır. Babanın sadece dölleyici rol oynadığı ana soylu toplumlarda dayı, yeğenlerinin birinci dereceden sorumlusu ve varisidir. Aile içindeki bu bağlardan dolayı dayı hukuku ortaya çıkmıştır.

Zamanla gelişen toplumda aile kurumunun oluşması ve baba otoritesinin çocuk üzerinde etkisinin azalması, dayının sahip olduğu güçlü statünün sarsılmasına yol açmıştır. Bu noktada dayı-baba gerilimi ortaya çıkmıştır. Baba otoritesinin toplumda tamamen kabul edilmesiyle, zamanla dayının toplumsal rolündeki değeri azalmaya başlamıştır. Ancak kültürün kökenlerinde güçlü bir rol oynayan dayının kültürel bellekte halâ önemli izleri mevcuttur. Söz konusu dayı hukukunun ana soylu toplumdan baba soylu topluma geçişte yaşadığ 1 değişim ve dönüşüm ortaya konulacak, Türk kültürü içindeki izleri takip edilip kalıp ifadeler, anlatılar ve halk uygulamalarıyla açıklanacaktır. Kültürel pek çok unsurda yer alan dayı kelimesinin arka planındaki halk hukuku ortaya konulacaktır.

Anahtar sözcükler: Türk halk hukuku, dayı hukuku, Türk kültürü, atasözleri, deyimler

* Muğla Sıtkı Koçman Üniversitesi, Türk Dili ve Edebiyatı Anabilim Dalı Doktora Öğrencisi YÖK 100/2000 Somut Olmayan Kültürel Miras Proje Asistanı. beratsametkahraman@posta.mu.edu.tr. ORCID 0000-0003-4676-6928 / CC BY 


\begin{abstract}
A person wants to have a sense of belonging and a sense of origin within the cultural structure in which they are located. Relatives play a significant role in such a framework. Especially in primitive societies, the uncle occupies a privileged position and a protective role that is different from other relatives. In maternal societies where the father only plays a fertilizing role, the uncle is responsible as a first-degree relative and is also an appointed heir. Uncle law emerged due to such ties within the family.

The formation of a family institution in the developing society over time and the decrease of the influence of the father authority on the child led to a stronger status of his uncle to dissolve. At this point, uncle-father tension emerged. With the full acceptance of the paternal authority in society, over time, the value of the uncle's social role began to decline. However, the uncle, who plays a strong role in the origins of culture, still has important traces in cultural memory. The change and transformation of the uncle law from the matrilineal society to the paternal society will be explained, its traces in Turkish culture will be defined and explained through stereotypes, narratives and folk practices. The folk law at the background of the word uncle which takes place in many cultural elements will be revealed.
\end{abstract}

Keywords: Turkish folk law, uncle law, Turkish culture, proverbs, idioms

\title{
Extended summary
}

Humans have tended to reproduce from the moment they existed. Proliferation has made socialization a necessity. The feeling of security is at the core of this need. The security caused by socialization stems from the anxiety of existence. From the first societies to the present, humanity has provided its existence through institutionalization within the society. Every individual in the society has been regarded as valuable as the society and ensuring their safety has been the fundamental principle. At this point, security has been kept related to first degree closeness and kinship relationship. The close relatives of every born child were those he could trust first degree. This situation is determined as a verbal but a definite law in folk law. It is not possible to determine the father of a child born in primitive society.

Studies conducted in primitive societies show that this folk law, which existed in the early times of humanity and has become an archetype in today's modern societies, is still alive. In primitive societies, uncle has a different status than other kinship relations. Just as the uncle has public and responsibilities over his nephew, the nephew has rights over his uncle. This reflects the necessity of social existence on the basis of mutual uncle-nephew relationship.

The cultural stages of societies have changed the nature of kinship relations. While the phenomenon of reproduction was an act based on unification in the early days, it occurred within the framework of the institution called marriage with the development of societies. 
Reproduction based on unification is a family structure where the father has no role other than insemination and the society does not define a legal obligation. The reason why the main nobility is prioritized is the lack of active father role. Uncle law emerged as a necessity of this period. In the future, the family institution based on marriage was formed with the formation of the mother and the father with certain legal responsibilities. The purpose of marriage is to know in advance the father of the child that the married woman will give birth to, and to secure the care and safety of the child with a society-approved guarantee. In this structure, status started to pass to the father with the family structure based on marriage. The society has never taken the uncle, which is the security mechanism, out of the systematic pattern. His uncle had to share his power with the father. This situation caused uncle-father tension, and it was reflected in the verbal culture products, which are accepted as folk law laws. Proverbs and idioms show the evolution of uncle law with the change in the structure of the family institution in society.

In the article, a classification trial was made by examining the stereotypes about the uncle. Paternity law was examined and classified in three separate periods. The period of family structure based on unification, in which his uncle was the sole authority, was called the First Conscious Discourse Period. With the emergence of the marriage institution, the period in which the uncle shared his authority with the father and there was conflict and tension was called the Second Conscious Discourse Period. The period when the marriage institution is completely settled and the authority of the uncle remains in the unconscious memory is defined as the Period of Unconscious Discourse.

It covers the first times of humanity in the First Conscious Discourse Period. In this period, the word uncle in mold expressions directly refers to the mother's brother and the child's uncle. Since Turkish society continues its existence as a modern society, the expressions of this period are very few in the stereotypes. However, the strong legal structure of this period can be felt. For example, Who is your daddy to mule? They said, my uncle is horse, the word uncle in the phrase of the mold shows the effort to attribute the ancestry to the uncle who has a superior status.

In the Second Period of Conscious Discourse, society provided the necessary dynamics of existence. Family structure based on reunification has evolved into a family structure based on marriage. With the father factor, the first degree significance of the expressions of the uncle started to decrease. For example, the phrase Work fell to uncle expresses the power of uncle law even when the father played an active role. In the society where the father's authority has begun to form, the father is not yet active. Therefore, he has to share his authority with his uncle. As a security mechanism, the uncle has always existed in the society during this period.

In the Period of Unconscious Discourse, the family structure based on marriage has been institutionalized as the main means of reproduction. This period covers the Second Conscious Discourse Period and our present. The word uncle in the stereotypes does not in any way refer to the uncle who is directly related to kinship. It refers to maternal law as a 
remainder of the primitive period. For example, Do you have an uncle in Ankara? The uncle in the discourse does not refer to the uncle with kinship ties. Unconscious collective memory conditionally reminisces uncle law. Remembering the status of the uncle and the necessity of protection in the primitive period, this law is accepted unconsciously. If the word uncle in the expression is removed, and another word of relatives is substituted for it, there will be no logical connection between the culture and it will seem strange. This shows the unconscious existence of uncle law.

It is seen that the privileged nature of the uncle is unconsciously preserved not only in molded expressions, but also in various Turkish folk culture elements and practices. The uncle is always seen as a status holder in narratives and various marriage rituals. The basis of all the examples given in the article is the uncle law, which has been extending from the beginning of the First Conscious Discourse Period to the present day.

\section{Giriş}

İnsanoğlu çoğalmaya, zaman içinde bir arada yaşamaya ve toplumsallaşmaya ihtiyaç duymuştur. Toplum olabilmenin temelinde güvenliğin gerekliliği vardır. Güvenlik duygusu, kendine özgü bilgi birikimi, değerler sistemi ve kurumlaşmanın oluşumuna yol açmıştır. Güvenlik tehditlerine karşı toplumun almış olduğu önlemler, insanlar arası ilişkilerde ortaya çıkar. Buna bağlı olarak toplum içinde fertlerin statüleri belirlenmiştir. Güvenme ve yakınlık kurma, birey-birey ilişkilerine akraba boyutu kazandırmıştır. Bir kişinin yakın akrabaları, birinci derecen güvenebileceği kişiler olmuştur (Bıçak, 2014: 170).

Akraba bağlarının güvenlikle olan ilişkisi, ana soylu aile düzeninin görüldüğü günümüz ilkel toplumları örnek alınarak bakıldığında dayının diğer akrabalara göre ayrıcalıklı bir statüye sahip olduğu görülür. Bu toplumlarda soy, ana soyu üzerinden yürür, çocuklar ve mülkiyet ana üzerinden geçer. Veli yetkisi ise dayıdadır (Bachofen, 1997: 19-20). Ana soylu topluluklarda, çocuklar ve aile mülkü üzerindeki ayrıcalıklara anadan çok dayı sahiptir (Şenel, 1997: 230) Dayının statü sahibi olmasının nedeni, doğan yeğeninin güvenliğini sağlama zorunluluğuna dayanır. Toplumda oynadığı rolle hak ve sorumlulukları belirlenir. Bir insanın değeri, topluluk hayatının gerektirdiği iş bölümüne yaptığı katkıya göre belirlenir. Toplum tarafından onaylanmış bir insan, başka insanlar için önemli bir kişi ve bireyleri bir birine bağlayan zincirin bir halkası haline getir (Adler, 2000: 119). Dayı-yeğen ilişkisinin sahip olduğu toplumsal gereklilik, dayılığın ne denli önemli ve onaylanan bir konum olduğunu gösterir.

Toplumların geçirmiş olduğu kültürel evreler akraba ilişkilerinin mahiyetini değiştirmiştir. Bu değişikliğin temelinde, çoğalmanın kurumlaşması vardır. Çoğalma, birleşme ve evlilik olmak üzere iki farklı şekilde sağlanmıştır. Birleşmeye dayalı çoğalma, babanın dölleyicilik dışında aktif bir rolünün olmadığı aile yapısıdır. Evlilik yoluyla çoğalma ise, gelişen toplumsal yapı ve artan nüfusa bağlı olarak aile kurumunun oluştuğu yapıdır. Evliliğin amacı, evlenmiş kadının doğuracağı çocuğun babasını önceden bilmek, çocuğun bakımını ve güvenliğini toplumca onaylanmış bir güvenceye bağlamaktır (Güvenç, 2002: 243). Birleşmeye dayalı aile yapısında dayının sahip olduğu statü, evliliğe dayalı aile yapısıyla babaya geçmeye 
başlamıştır. Toplum, güvenlik mekanizması olan dayıyı hiçbir zaman sistematik örüntüden çıkarmamıştır. Kültürel oluşumun değişmesine bağlı olarak zamanla dayı algısında azalma olmuştur. Güçlü bir statü sahibi olan dayı, erkini babayla paylaşmak zorunda kalmasıyla otorite gerilimi yaşanmıştır. Dayı-baba arasında yaşanan mücadele, toplumun görüşlerini, hayata bakış açılarını, duygu ve düşüncelerini yansıtan kalıp ifadelere yansımıştır. Toplumun binlerce yıllık denemelerinden ve buna dayanan düşüncelerinden, kültürel bellekte devam eden atasözleri ve deyimler, köken bilgilerinin izlerini taşır. Atasözleri ve deyimler Tanrı, peygamber sözü gibi insanların ruha işler. Atalar sözü Kur'an'a girmez, yanınca yelişür ifadesi, Türk kültüründe ataların sözüne verilen önemi ortaya koyar (Aksoy, 2017: 15).

Atasözleri ve deyimleri oluşturan kelimelerin, kökenlerinde toplumun kültür dünyasının işaretleri vardır. Toplumsal duyguların, düşüncelerin özünü oluşturur (Çobanoğlu, 2004: 2). Kökenlerden gelen bu bilgi, sosyokültürel deneyimler ve değerleri yansıtır (Dursun, 2015: 151). Kalıp ifadelerin çözümlenmesi, anlamlandırılması toplumların geçmişleri ve uygarlaşma sürecindeki evreleri hakkında bilgiler verir. Bu yolla kültürdeki değişmeler, kalıp ifadelerin incelenmesiyle ortaya çıkartılabilir. Zaman içinde dayılığın toplumsal algısı gözlemlenebilir.

Zaman içindeki değişikliği tespit etmek için atasözleri ve deyimler üç ayrı dönem içinde tasnifi yapılmıştır. Dayının salt otorite olduğu, birleşmeye dayalı evlilik dönemine Birinci Bilinçli Söylem Dönemi, evlilik kurumunun ortaya çıkmasıyla dayının otoritesini babayla bölüştüğü, çatışmanın ve gerilimin olduğu döneme İkinci Bilinçli Söylem Dönemi, evlilik kurumunun tamamen yerleşmesi ve dayının otoritesinin bilinçdışı bellekte kaldığ döneme ise Bilinçdışı Söylem Dönemi denilmiştir.

Tasnif denemesinde kullanılan bilinç ve bilinçdışı kelimeleri, psikolojinin psikanaliz yaklaşımında kullanılan terimler değildir. Bilinç, kişinin doğrudan tanıdığı ve farkında oldu$\breve{g} \mathrm{u}$ zihin yapısıdır. Psikanaliz yaklaşımda ise bilincin bireyselleşme sürecine ego adı verilir. Ego, bilinçli zihnin örüntüsüdür. Bilinç düzeyindeki algılardan, anılardan ve duygulardan oluşur (Geçtan, 1998: 172-173). Bilinçdışı kavramını Freud, kişinin birçok davranışını akıl, bilgi ve iradenin denetiminden kaçan veya ondan saklanan bir mekanizma şeklinde açıklar (Güvenç, 2002: 36). Jung ise bilinçdışını, arketip adını verdiği ortak duygusal ve zihni davranış kalıplarını miras alan, onların ürünleri olan sembolik fantezilerin, düşüncelerin ve eylemlerin pratik insan davranışına yansımaları olduğunu ifade eder (2017: 300). Çalışmada bilinç kelimesi, kişinin dayı söyleminde bilinçli bir şekilde annesinin erkek kardeşini işaret eder. Kan bağına dayalı doğrudan bilinçli söylemdir. Bilinçdışı kelimesi ise dayı kelimesinin anlamını yitirmesi, doğrudan bir akrabayı işaret etmemesi, ancak kolektif bellekte otorite olarak bir karşılığının olması anlamında kullanılır.

\section{Akraba ve evliliğin sistematik yapısı}

Akraba, kan bağıyla birbirine bağlı olan kimseler, akraba olma ise evlilik yoluyla yakınlık kurma durumuna denir (TDK, 1998: 63). Akraba, pek çok toplumda Evlilik Öncesi ve Evlilik Sonrası olmak üzere iki temel yapıya sahiptir. Evlilik öncesi, kişinin doğumuyla 
tanıdığı, yakınında bulunan kan bağına dayalı akrabalıktır. Evlilik sonrası akrabalık ise iki kişinin karşılıklı ilişkisinden doğan, iki farklı akraba grubunun edindiği ilişki örüntüsüdür. Evlilik öncesi ve evlilik sonrası akrabalık, karşılıklı sosyal bir ilişki, görev ve sorumluluk sistemidir (Güvenç, 2002: 236-243). Akraba ve akrabalık/akraba olma evlilikle birbirinden ayrılır. Akrabalık sonradan edinilir. Ana-analık kavramlarında olduğu gibi sonradan edinilen kişi “-lık, -lik” ekiyle öncesinden ayrıldığı düşünülebilir. Akrabalık sisteminin temelinde fertlerin birbirine karşı hak ve görevleri vardır. Hak ve görevlerin mahiyetini ve ilişki boyutunu belirleyen unsur hukuktur (Dursun, 2016: 137).

Kültürel varoluşun ve düzenin sağlanabilmesi için toplum, hukuksal bir yapıya ihtiyaç duymuştur. İlkel aklın yasa/hukuk ihtiyacını keşfi, toplum olmanın başlangıcını göstermektedir. (Bıçak, 2014: 122). İlkellerde yazılı hukuk, çağdaş toplumlarda görülen hukuk normları ve yasaları yoktur. Bu durum, ilkelerde hukuk olmadığını göstermemektedir. Normatif sistem denilen ahlak kuralları, estetik ölçüler, iyi davranışlar vb. olumlu tutumlar hukuk değerindedir. İlkellerde hukuk algısı, kolektif davranış ve düşünce yapısına sahiptir. Ferdiyetçi bir tutum, şahsi istek ve davranışlar ilkel toplumda kabul edilemez. Bu hukuk algısına halk hukuku denilmektedir (Dursun, 2016: 54-55). Halk hukuku, toplumun gelenek, görenek ve alışkanlıklarından beslenen, kalıp tutum ve davranışla şekillenerek günümüze taşınan, toplumdaki işlevsellikleriyle dinamizmini kaybetmeyen, süreklilik göstererek bir sonraki nesle aktarılan, toplumun temeli olan ailede baba otoritesinden başlayarak bir otorite tarafından onaylanan ve desteklenen sözlü hukuk kurallarıdır (Dursun, 2016: 56). Halk hukuku, bireyin topluma, toplumunda bireye karşı sorumluluklarını tanımlamaktadır. Bundan dolayı doğan her bir çocuğa, öncelikle toplumun sorumlulukları daha sonra ise çocuğun toplumuna karşı yükümlülükleri vardır. Toplum-çocuk ilişkisinin temelini ise aile kurumu oluşturur.

İlkel dünya için aile, birleşme ve evlilik olarak ayrılır. Birleşmeye dayalı ailede, babanın belirli bir statüsü yoktur, çünkü biyolojik babanın tespiti mümkün değildir. Birleşmeye dayalı yapısında baba, sadece dölleyici rol üstlenir. Doğan çocuğun sorumluluğu, annenin en büyük erkek kardeşine, dayıya verilir. Dayı, toplum çocuk ilişkisinde rol oynayan ilk akrabadır. Bundan dolayı en güçlü statüye sahiptir. Toplumdaki kadınların erkek kardeşleri, bütün bir toplumun babalık sorumluluğu almış olur. Klan içi evlenmek, toplumun temel dinamiklerini sarsacağı için uygun görülmez. Toplum içi bütün kadınlar aynı toplumdaki bütün erkekler için yasaklı dişi kabul edilir (Reed, 1982: 224). Egzogami kuralının uygulanmasının temelinde de bu görüş yer alır. Egzogami, iki fark toplumun kız alınıp vermesine, karşılıklı dünür olunmasına denir. Bu yapı Türk kültüründe oldukça güçlü bir hukuktur. Yenisey yazıtlarında yatta tünürime ifadesi, yad eldeki dünürüme anlamına gelir. Dede Korkut hikayelerinde Kazan Bey'in oğlu yad kızı helalime destur versin diye vasiyet eder. Deli Dumrul, yad kızı helalim var der. Egzogaminin izleri geçmişten bu güne türkülerde de görülür. Yad ellerden sitem, el oğlu, yad eller ald $\imath$ vb. ifadeler, egzogami hukukunun gücünü gösterir (İnan, 1998: 341). Yedi kat yabancı ifadesi de, Türk kültüründe yedi göbek uzaktan evlenme geleneğine olan bağlılığı gösterir (Dursun, 2016: 106). Egzogami, aile olmayı zorunlu kılan ve aileyi korumaya yönelik bir hukuk uygulamasıdır. Kökenleri dölleyici baba döneminin başlangıcına kadar uzanır. 
Dölleyici baba, belirli bir sistemin ve faydacılığın karşılığı olarak ortaya çıkar. Her erkek döl verici veya her kadın döl alıcı değildir. Belirli bir hukuk gözetilir. İki farklı konumda bulunan toplumun erkekleri karşılıklı dölleyici rol üstlenir. Genellikle kıyı ve iç toplum arasında bu ilişki görülür. Dölleyiciliğin ötesinde toplumlar arasında karşılıklı ürün takası da görülür. Kıyı toplumu deniz mahsullerine karşılık, iç toplumdan tarım ürünü alır. Bu karşılıklı ilişkiye simetrik alışveriş denir (Özcan, 1998: 96). Malinowski, simetrik alışverişi iktisadi, siyasi ve dini birlikteliğe dayanan karşılıklılık ilkesi altında ele alır. Malinowski’ye göre romantizmden uzak kardeşlik (yasaklı dişi) algısı, cinselliğin yıkıcılığının önüne geçer. Bu durum salt faydacılığı sağlar (1987: 46).

Faydacılık toplumun iç dinamiklerinde de sürdürülür. Doğan her çocuk belirli bir koruma ve yetiştirme sistemine tabi edilir. Bu sisteme genel olarak eğitim kümesi denilir. Doğan çocuk cinsiyetsiz kabul edilir ve erginlik dönemine kadar anne başta olmak üzere kadın eğitim kümesi içinde yetişir (Reed: 1982: 117).

Erkek çocuk, zamanı geldiğinde besleyen ve koruyan ilk varlığın dişiliğindeki yüceliği ifade eden anneden ve bu kümeden çıkmak zorundadır (Campbell, 2013: 130). Çünkü erginlik dönemiyle kişi bir kimlik kazanmaya hazır hale gelir. Dayı merkezli bir erkek grubuna geçmesi gerekir. Erkek çocuklarının erginlenmesi için temel şart, anneden -kutsal annenin koruyuculuğundan- kopuştur. Çocukların anneden ayrılmalarının nedenini, çocukluk dünyasından, anaerkil yapıdan, sorumsuzluk ve cinsiyetsizlik durumundan kopuş olarak nitelendirmektedir (Eliade, 2015: 35).

Eliade'nin ifade ettiği erginlenme ve anneden kopuş eyleminin pragmatik gerekçesini Reed, küme eğitim gruplarına giriş olarak değerlendirir. Küme eğitim grubu, çocukluktan erişkinliğe geçiş sonrası eğitim grubudur. Erkek çocuklar erginlenme sürecinden sonra dayı kontrolü altında erkeklerden oluşan bir gruba dâhil edilir ve burada ortak avlanma, savaş ve kişilik eğitimi alır.

\subsection{Dayı hukuku}

Dayı, akraba sistemi içinde tanımlayıcı bir hısımlıktır, ancak sahip olduğu toplumsal sorumluluklarından dolayı sınıflayıcı özelliğe de sahiptir. Dayı, yalnızca bir kişiyi ya da ilişkiyi değil, karşılıklı bir sosyal birlikteliği kapsar. Sözgelimi, dayı-yeğen ilişkisi, karşılıklı görev ve sorumlulukları gösterir. Sistem içinde kime dayı adı verilirse, onunla kişi arasında dayı-yeğen ilişkisine benzer bir ilişki vardır (Güvenç, 2002: 237). Dayı-yeğen ilişkisi dayı hukukuna dayanır. Kazak ve Kırgız Türklerinde bu ilişkinin bir takım somut uygulamaları vardır. Yeğen, dayısının malından üç kez çalabilir. Çaldığı mallar yeğen hakkı olarak görülür, ancak çalma belli bir takım hukuk kurallarına bağlıdır. Yeğen, dayısının atını, köpeğini ve savaş aletlerini çalmaz. Ayrıca yeğen, anasının kabilesine ait bir kişinin toyunda, babasının kabilesine ait bir toydan daha fazla mevki (orun) ve pay (ülüş) talep edebilir. Yeğenin çocuğu yeğen hakkı kullanmaz. İnan, dayı-yeğen hakkının egzogaminin ilk devirlerinin karanlığına kadar uzandığına şüphe olmadığını söyler (1998: 289). 
Dayı adı verilen kişi, biyolojik anlamda annenin kardeşi olmasa bile ilişki boyutu değişmez. Kişinin arada kan bağı olmaksızın bir kişiye dayı veya yeğen şeklinde hitabı veya kan bağı olsa bile dayısı olmayan bir kişiye dayı-yeğen demesi de dayı hukukunun kapsayıcılığına girer. Çünkü dayı söyleminde evlilik, cinsel anlamda menfaat riski bulunmaz. Amca yeğeniyle evlenebilir. Ancak dayı, yeğeniyle kesinlikle evlenemez. İki kişi arasında hukuk ilişkisi kurulmuş olur. Bundan dolayı akraba sözcügü dayının asıl önemi, tanımlayıcı niteliğinden çok sınıflayıcı görevlerinden gelir (Güvenç, 2002: 237). Dayının sahip olduğu hak ve sorumluluklar, toplumun dayıya olan bakışı, dayının akrabadan öte güvence haline gelmesini sağlar.

Dayı hukuku, ilkel toplumlarda dayının sahip olduğu sorumlulukları somut bir şekilde ortaya konar. Dayı, yeğenlerini toplumun çeşitli erginleyici ritüellerine hazırlamaktan da sorumludur. Malinowski, dayı için sadece toplumu ilgilendiren işlerde yeğenini geliştirmediğini, aynı zamanda toplumun kökenini açıklayan çeşitli masal, efsane gibi anlatıları da öğretmekle mükellef olduğunu ifade eder (1987: 41). Hoebel, Man in the Primitive World adl1 eserinde, dayı yeğenini çeşitli sınavlardan geçirerek toplumuna uygun bir erkek olduğunu meşrulaştırır. Eğer çocuk bu sınavı başarıyla geçerse dayı yeğenine unvan, hediye vb. ödüller vermektedir. Burada önemli olan, dayının sınayıcılığına ve denetleyiciliğine olan güvendir (Aktaran Ayaz, 2015b: 157). Erkek çocuk, eğitim grubuna dâhil olduğu andan itibaren toplumundaki kadınlarla ilişkisini keser ve her kadın onun için yasaklı dişi haline gelir. Aynı zamanda yemek yeme alışkanlığı da değişir. Buna bağlı olarak da sofra düzeni edinir. Dayısı ve çevresindeki diğer akraba erkeklerle kan akrabalığını tanır (Reed, 1982: 230-233). Bu noktada birleşmeye dayalı aile yapısında cinsel kimliğe dayalı gruplaşma, eğitim için gerçekleştirilir.

Evliliğe dayalı aile yapısı, dölleyici babanın birleşme sonrası anneyle birlikte yaşamasıyla başlar. Bu durum toplumsal yapının değişmesine neden olmuştur. Anne merkezli yapı varlığını sürdürürken, çocuğun yanındaki koruyucu erkek değişmiştir. Babanın annenin yanında kalmasıyla dayının yerini baba almaya başlamıştır. Hiyerarşik düzen de değişmiştir, ana soylu erkek otoritesiyle, baba soylu erkek otoritesi çatışmaya başlamıştır. Bu durum erkek erkine dayalı baba soylu yapının oluşmasına zemin hazırlamıştır.

Berna Ayaz, konu hakkında daha önce dolaylı bir araştırma yapmıştır. Dayılığı kült olarak ele alır ve kültün ortaya çıkışını anaerkil düzenle, yeni ortaya çıkan ataerkil düzenin çatışmasından doğduğunu ifade eder (2015: 156). Ancak dayı hukuku, mitik anlatılardan uygulamalara, kalıp ifadelerden halk anlatılarına yansımış, insanların toplumu oluşturduğu dönemden günümüze ulaşmış değerli bir statüdür. Malinowski bu durumu Trobriand yerlilerini kaynak göstererek açıklar. Hiçbir mitik anlatıda ve inanç merkezli uygulamada babadan veya kocadan bahsedilmediğini, bazı uygulamalarda babanın sadece görsel olarak bulunduğunu ifade eder. Yerlilere göre hiyerarşik düzen azdan çoğa önem sırasına göre; dölleyici baba, anne, dayı, dayının dayısı olarak ilerler (1992: 182).

Ralph Piddington, çeşitli törenlerde ailenin en yaşı üyesinin -ki en büyük dayı- mitik ölü atalardan söz ederken, ölü ataların soyunu kadının erkek kardeşine bağladığını ifade eder. Adanson Hoebel de dayının mirasının yeğenine kaldığını, dayının bütün toplumsal hak ve ayrıcalıklarının oğluna değil, yeğenine aktarıldığını söyler (Aktaran: Reed, 1982: 225). 
$\mathrm{Bu}$ bilgiler 1şında ilkel toplumda cinsiyetçi kimlik yapısına dayalı üstünlüğün olmadığı görülür. Pragmatik gerekçelerle dayı, çocukların resmi tek koruyucusudur. Birleşmeye dayalı aile kurumu otorite bakımından dayı merkezlidir. Evlenmeye dayalı aile yapısında her ne kadar baba ortaya çıksa da, dayı her zaman koruyucudur. Her iki aile türünde de çocukların sorumluluğunu üstlenen bir erkek vardır. Kadına, ana soyunun kutsallığına dayanan bir ayrıcalık atfedilmiştir, ancak cinsiyete dayalı üstünlük yoktur (Çakmak, 2015: 62).

\section{Türk kültüründe dayı hukuku}

Kelimeler, yaratıldığı kültür evreni hakkında bilgiler verir. Bir kelimenin sözlüğe girmesi, yaşayan anlamını sabitlemediği gibi değişimini de engelleyemez. Türkçe Sözlükte dayı: 1. Annenin erkek kardeşi, 2. (mecazen) bir kimsenin kayırıcısı olan, sözü geçen kimse, 3. Yaşlı erkeklere seslenme sözü, 4. Osmanlı İmparatorluğu döneminde Tunus, Cezayir ve Trablusgarp'ta seçimle başa getirilen kişi, anlamlarına gelir (1988: 535).

Dayı kelimesi, etimolojik olarak incelendiğinde Türkçe olmadığı görülür. Dayı kelimesi, Çin'ce tay- kelimesinden türetilmiştir. Çince'de tay- büyük anlamına gelmektedir. Göktürk yazıtları Bilge Kağan, Güney 11'de; Lisün Tay sengün (Li Ts'üan büyük general) şeklinde geçmektedir. Moyon Çor yaztında Tay Bilge Totok ve Altın Köl II'de Altun Tay Sangun ifadeleri de örnek olarak alınabilir (Sertkaya, 2018: 95-96).

Eski Türkçede annenin erkek kardeşi için büyük ağabey anlamına gelen tay-aga kelimesi kullanılmıştır. Eğer annenin erkek kardeşi iki tane ise, büyük için tay-aga, küçüğün akrabalık adı tay-aga-y'dır. tayagay- tayakay kelimesi vurgusuz orta hecenin düşmesiyle tagay-takay şeklini almıştır. tagat “dayı” kelimesi eski Uygur Türkçesi’nde Hsüang Tsang tercümesinde unvan olarak, Divanü Lügatit Türk’te, Codex Cumanicus'ta, Şecere-i Terakkime'de ise akrabalık bağı olarak dayı anlamında geçmektedir (Sertkaya, 2018: 113).

Dayı kelimesinin Türkçe Sözlükte yer alan dördüncü anlamı, kelimenin geçirdiği kültürel aşamaları gösterir. Birinci anlamı olan annenin kardeşi, kelimin en eski ve yalın haliyken, ikinci, üçüncü ve dördüncü anlamları, dayının kültür tarihi içindeki önemi üzerine inşa edilmiştir. Dayı, Osmanlı İmparatorluğu döneminde, askeri teşkilatlanmada da önemli bir unvan olarak kullanılmıştır. Daha çok denizcilikle uğraşan Kuzey Afrika eyaletleri halkından Akdeniz'de korsanlık yaparak meşhur olmuş denizcilere dayı unvanı verilmiştir. Bu eyaletlere Garp Ocakları denilmiştir. Eyaletlerdeki yönetim diğerlerinden farklıdır. Beylerbeyi tayin edilmesine rağmen, idari işler divan adı verilen eyalet meclisine bırakılmıştır. Meclise başkanlık eden kişiye de dayı adı verilmiştir. Eyaletlerin güvenliğini sağlamak üzere görevlendirilen yeniçeri ağası ve bütün subaylarla denizcilerin reisleri de divan üyesidir. Dayılık bir yönetim statüsü olduğu için, Yeniçeriler arasında iktidar mücadelelerine ve huzursuzluğa neden olmuştur (Maksudoğlu, 1994: 59-60).

Dayı zamanla sıfat halinden isme doğru değişim süreci geçirir. Dayıya yönelik anlam, zamana ve toplumsal yapıya bağlı olarak anlam tabakalaşması yaşamıştır. Halbwachs, bu tabakalaşmayı ardışık iki döneme tekabül eden hatıralar olarak değerlendirir. Düşünce tabakasının (akışının) durum/olay odaklı psikolojik veya tecrübeye dayalı duygu olduğunu ifade 
eder. Bundan dolayı tek ve evrensel bir zaman mümkün olmadığı için düşünce ve ifadeler de zaman içinde tabakalaşarak değişir (2018: 153-155). Bu tabakalaşma, kültür tarihini katmanlar halinde yansitan kalıp ifadelerde görülür.

Kalıp ifadeler, geniş grup kimliğinin (toplumun) garanti bilgilerin bütünü olarak değerlendirilir (Assmann, 2015: 98-99). Kalıp ifadeler, ilkel toplumlarda bireyin okulu ve yeryüzünde yaşama kılavuzu olarak nitelendirilir (Çobanoğlu, 2004: 2). İnsanlığın ilk tecrübelerinden günümüze uzanan süreçte, bir akıl yürütme ve aklını kullanma pratiği olan kalıp ifadeler, sadece işlevsel bir yana sahip değil, sosyolojik ve psikolojik yanları vardır. Toplumun davranış biçimini, dünya görüşünü, töresini, inancını, hayat tecrübesini de ortaya koyar (Dursun, 2015:152).

İfade etmeye veya söylemeye değer bir olgunun yaşatılması, ifadenin arkasındaki psikolojik veya sosyolojik kabullerden kaynaklanır. Buna bağlı olarak, dayıya farklı dönemlerde farklı anlamlar yüklense de, toplumun düşünce ve deneyimlerini yansıttığı için yaşatılmaya değer bulunmuştur. İlkel toplumdan modern topluma dayı kelimesi zamanla anlamında daralma yaşamıştır. Bu süreç, kalıp ifadelerde kullanılan dayının karşıladığı anlamlardaki farklılıkla görülür. Anlam tabakalaşmasını görünür hale getirmek için çalışmada dayıyla ilgili bir sınıflandırma denemesi yapılmıştır.

Kalıp ifadelerde geçen dayı kelimesi, üç temel döneme ayırarak incelenebilir. Bu dönemler; Birinci Bilinçli Söylem Dönemi, İkinci Bilinçli Söylem Dönemi ve Bilinçdışı Söylem Dönemi olarak adlandırılabilir. Dönemlerin ayrımı, toplumların aile kurumu olgusundaki değişmelere göre yapılmıştır. Bilinçli söylem denilmesinin nedeni, doğrudan dayının kastedildiği, anlam olarak annenin kardeşi dayının anlaşıldığı ifadelerden dolayı denilmiştir. $\mathrm{Bu}$ dönemin birinci ve ikinci olarak ikiye ayrılmasının sebebi, birleşemeye dayalı evliliğin, yerleşik babayla oluşan aile kurumuna dönüşmesidir. Bilinçdışı söylem denilmesinin gerekçesi ise evliliğe dayalı aile kurumunun yerleşmesine bağlı olarak, dayının öneminin oldukça azalması, değerinin unutulmaya başlanması ve yerini babanın almasıdır. Bu dönemde dayı, iç kültürel değerini yitirmiş, bilinçli söylem dönemlerinin bakiyesi olarak bilinçdışında toplumsal kabul olarak kalmıştır.

Üç temel dönem içinde Türk kültüründe yer alan dayı hukukuna ilişkin kalıp ifadeler, halk anlatıları ve uygulamaları, dayının dönemsel anlam karşılığına göre sınıflandırılmıştır.

\subsection{Birinci bilinçli söylem dönemi}

Birinci Bilinçli Söylem Dönemi, düşünce ve deneyim mekanizmalarının paralel olduğu, salt iletişim, iktisadi ve siyasi birliğin zorunlu yaşandığ 1 , temel amacin varoluş ve sürdürülebilir yaşamın olduğu dönemi kapsar. Bu dönem, deneyimlerin bir düşünce sistematiği oluşturduğu süreçtir. Buna bağlı olarak dayı ve dayılık kurumu, birinci koruyucu ve denetleyici mekanizmadır. Bu dönem, mutlak sonlu bir dönem değildir. Toplumun değişimine veya değişme gereksinimine bağlı olarak sonlanabilir. Malinowski’nin yakın tarihte üzerlerinde çalıştıkları ilkel kabilelerde dayılık kurumunun hala Birinci Bilinçli Söylem Dönemi’nde olmasının nedeni de budur. 
Bu dönem, temel ana soylu yapı olarak kabul edilebilir, çünkü toplumda kadın ve erkek eğitim grupları varlığını sürdürür. Doğan çocuk ergenliğinden itibaren grup değiştir ve aile yapısı birleşmeye dayalıdır. Bundan dolayı bu dönemde dayı, en yalın ve en kuvvetli sürecini yaşar. Dayıya ait söylemler birinci dereceden anlamıyla doğrudan çocuğun annesinin erkek kardeşini, dayısını ifade eder. İkinci derecen anlam bu dönem için geçerli değildir.

Dayı kelimesinin doğrudan bu dönemi yansıttığı kalıp ifade oldukça azdır. Katıra baban kim? demişler, dayım attır demiş (Aksoy, 2017: 349) ifadesi, kusurlu yanını gizlemeye çalışan, sadece övünebileceği yanını göstermek isteyen bir kişi için kullanılır. Ayrıca kalıp ifadede yer alan katır kelimesi dayı hukukuyla ilişkilidir. Çünkü katır, erkek eşekle dişi atın birleşmesinden meydana gelen ve üreyemeyen bir canlıdır. Katıra babasının kim olduğu sorulduğunda dayısını söylemesi, zürriyetini dayısıyla açıklaması ve babasını yok sayması, Birinci Bilinçli Söylem dönemini kapsayan dayı hukukundan dolayıdır. Ayrıca, dayım attır ifadesinde yer alan at kelimesinin özellikle kullanılması, ana soyunun yüceltilmesinden ileri gelir.

Dayının övünç kaynağı olarak kullanılması, köken bilincinin dayıya atfedilmesi ve dayının babadan üstün tutulup öncelenmesi önemlidir. Dayı ve baba arasındaki gerilim ve yaşanan sancılı süreç açıkça görülür. Kültürel bir değişme belirli bir süreç içerir. Mümtaz Turhan bu durumu üç aşamalı (taşıyıc1-toplum-kültür) kabul süreci olarak değerlendirir. Kabul ise ancak fertlerin değişikliği denemesiyle sağlanır (2016: 42). Gerek dayı, gerek baba statüsü bu dönemin sonlarında sınanmaya başlamıştır.

\section{2. İkinci bilinçli söylem dönemi}

İkinci Bilinçli Söylem Dönemi, düşünce ve deneyim mekanizmasının ihtiyaçlara paralel olarak değişmeye başladığı, zorunlu iktisadi ve siyasi birliğin zamanla varoluş çabasından, gereksinim ve tüketime dönüştüğü dönemi kapsar. Bu dönemde toplum, kendi varoluşu için gerekli temel dinamikleri sağlar, bu dinamikler üzerine özel yetiler kazanmaya başlar. Dayının, yerini babanın almaya başlaması da bu özel yetilerin sonucudur. Birleşmeye dayalı aile yapısı, evlenmeye dayalı aile yapısına dönüşür ve dayıya ait söylemlerin birinci dereceden önemi azalmaya başlar.

Bu dönemde dayı ve baba birlikte varlığını sürdürür. Baba, ailenin koruyucusu konumundayken, dayı toplumun koruyucusu olma özelliğini korur. Baba ve dayının değer varlıkları birbirine eşit değildir. Dayı daha baskın bir yapıya sahiptir. Baba, aile kurumun bir ferdi olarak görülür. Dayıya ait söylemler, birinci dereceden ve ikinci derecen anlamlar taşır. Gerçek anlamda (annenin kardeşi) dayı kastedildiği gibi, dayılık (kan bağı olmayan) atfedilen kişiler de (otorite) söylemin anlamına dâhil edilir.

Bu döneme ait kalıp ifadeler ve örnekler, birinci döneme göre daha fazladır. Örneklerde dayı-baba gerilimi açıkça görülür. Ayrıca söylemler keskin bir şekilde yargı bildirir.

İş dayıya düştü/düşer ifadesi, (https://sozluk.gov.tr/?kelime= $\mathrm{i} \% \mathrm{C} 5 \% 9 \mathrm{~F} \%$ 20d ay $\% \mathrm{C}$ $4 \% \mathrm{~B} 1$ ya $\% 20 \mathrm{~d} \% \mathrm{C} 3 \% \mathrm{BC} \% \mathrm{C} 5 \% 9 \mathrm{Ft} \% \mathrm{C} 3 \% \mathrm{BC}$ ) dayının değişen statüsünü gösterdiği gibi dayı hukukunun ne denli güçlü olduğunu da yansıtır. İşin dayıya düşmesi, bir işin başarılamaması üzerine dayının bu işi kesin bir şekilde yapacağına kanaat getirilerek söylenir. Dayı, 
ikinci plana itilir. Dayıdan önce bir otoritenin varlığı anlaşılır ve bu kişi babadır. Ancak, baba otoritesinin henüz oluştuğu toplumda, baba yetkin değildir. Bundan dolayı otoritesine, erkine sığınılan kişi her zaman dayı olur. İşin dayıya düşmesi, dayı hukukunun gücünü gösterir.

Kız halaya, oğlan dayıya çeker (Aksoy, 2017: 398) ifadesi, toplumdaki eğitim kümelerinin varlığını gösteren, pragmatik gerekçelerin korunduğu döneme ait söylemdir. Kızın kadın grubuna, oğlanın erkek grubuna dâhil edilmesi, ilkel toplumlarda ortaklığın ilk evresidir. Ortak kimlik yaratımının bir gerekçesidir (Assmann, 2015: 148-149). Kızın halaya çekmesi baba soyunun, oğlanın dayıya çekmesi ise ana soyunun yüceltilmesidir. Çekme ibaresi, aile karakteri, huy güzelliği vb. olumlu beklentiler için kullanılmıştır. Her iki soyun da eşit tutulması, var olan gerilimi azaltmaya yöneliktir.

Bölge ağızlarında kullanılan, genel kullanıma yayılmayan kalıp ifadeler de vardır. Özellikle kırsal yaşamda kullanılan kalıp ifadelerde geçen dayı kelimesi ve onun karşıladığı dayı hukuku, toplumun kültürel belleğinden gelen derin bilgiyi gösterir. Örneğin; Dayılar yeğenleri yükseltir, amcalar batırır (Aksoy vd., 2009: 86) ifadesi İkinci Bilinçli Söylem döneminin soy gerilimi ruhunu anlatır. Dayıların yeğenlerini yücelttiğini, amcaların ise batırdığını söylemek, alt metin okumalarında aslında amcaların dayılardan daha etkin rol oynamaya başladığını işaret eder. Toplumsal kabul, dayının statüsünde ve değerinde azalmayı kabul etmekte güçlük yaşar. Ĕ̆ri ăgaca yayım, her gördügüune dayım deme! (Aksoy vd., 2009: 103) ifadesi, düşünce pratiği açısından dayıya olan güveni yansıtır, ancak aynı zamanda dayı, kan bağı olmadan dayılık atfedilenlere karşı oluşan bir güvensizliği de verir. Bu ifade, toplumda bazı kişilerin kültürel yapıyı istismar ettiğini gösterir. Çünkü dayı hukuku zayıflamış ve yaptırım gücü azalmıştır. Güvenme dayına, azık (ekmek) al yanına (Aksoy vd., 2009: 130) söylemi de, değişen toplumsal düzenin uyarısıdır. Kolektif yapıdan bireyselleşmeye geçen toplumların değer yargılarının değiştiğini ifade eder. Dayıya karşı güvensizliğin oluşması da, öncesinde veya hâlâ dayıya olan güvenin işaretidir. Dayım adam olmadıktan sonra, ha şehirli olmuş ha köylü (Aksoy vd., 2009: 86) ifadesi de, dayının misyon olarak toplumun ona yüklediği görevi yerine getirmesi yönündeki gerekliliği bildirir. Dayının adam olmasında aranan nitelik, onun otorite ve koruyucu olma özelliği üzerine inşa edilmiş dayı hukukuna uygun davranma zorunluluğudur.

\subsection{Bilinçdışı söylem dönemi}

Bilinçdış1 Söylem Dönemi ise, İkinci Bilinçli Söylem Dönemi ve günümüzü kapsayan süreçtir. Bu dönemde dayı, birinci ve ikinci dereceden anlamından uzaktır. Dayı, üçüncü bir anlam olan, bilinçdışı anlam kazanır. Bu dönem kalıp ifadelerde kullanılan dayı, sadece ses uyumu ve bilinçdışı kabule dayanır. İfadeyi kullanan da, ifadenin muhatabı da dayının birinci ve ikinci anlamını algılayamaz. Çünkü dayının anlam karşılığı dayı hukukuna bağlı koruyucu bir statü değil, herhangi bir tanıdık halini almıştır. Ancak bu herhangi bir tanıdık da tıpkı dayı gibi siyasi anlamda güçlü, güvenilen veya olumlu iletişim kurulmak istenilen bir kişidir.

Halk arasında kullanılan Ankara'da dayın mı var? ifadesi, kişinin işini statü anlamında yüksek bir tanıdığı aracılığıyla yaptırmasını durumunda kullanılır. İlkel aklın, dayıyı yükle- 
diği anlam ve pratiklik görülebilir. Dayı, yeğene hak olarak diğer kişilerden daha fazla ayrıcalık tanır. Yeğenini kayırır ve bu durumu dayı oluşuyla meşrulaştırır. Ancak bu söylemdeki dayı kelimesi, birinci dereceden anlamıyla dayıyı işaret etmez. Dayının yerini almış olan ve güvenilen herhangi bir kişiyi sembolize eder. İfadeyi kullanan kişiyle bunu duyan kişi, asla annesinin erkek kardeşinin kastedildiğini düşünmez. Kolektif bellek, dayıyı bilinçdışı kabul eder ve yadsımaz. Dayı kelimesiyle, amca, hala, teyze vb. akraba kelimeleri yer değiştirilse, ifade ve kültür arasında mantık örüntüsü kurulamayacağı için insanlara tuhaf gelecektir.

Köprüyü geçinceye kadar aylya dayı demek (Aksoy, 2017: 372/1884) ifadesi, faydacı ve çıkarcı bir akıl yürütme gerekliliğidir. Metafor anlamıyla köprü bir zorluğu teşkil eder. Ayı ise tanınmayan bir kişinin gücüne boyun eğmek anlamına gelir. Ayı kelimesinin Türk kültürü içinde de otorite anlamı vardır. Şamanizm'de şamanın hayvan anası ayı, aynı zamanda onun koruyucu ruhudur. Şamanın geçmişi ve geleceği görme gücünü, aydınlanmasını ve kehanette bulunmasını sağlayan bağımsız ruhtur (Bayat, 2016: 102). Bundan dolayı ayıya sayg1 duyulmaktadır. Ayı İdi Koca İdi masalı, ayı tarafından kaçırılan bir kızın, bir süre sonra köylüler tarafından ayı öldürülerek kurtarılmasını anlatır. Masalın sonunda kız öldürülen ayıya kocam diye ağıt yakar (Önal, 2011: 414). Kadının tutumu, kaba da olsa, ayı da olsa kocası olduğu yönündedir. Masalda ayının seçilmesinin nedeni, kültürel bellekteki otorite algısıdır. Halk arasında kullanılan Ayıya dayı demek ifadesi de, yabancı veya kaba bir otoriteyle dayı hukukuyla yaklaşmak, samimi bir iletişim kurma çabasıdır. Aynı şekilde, yabancı bir kişiye dayı! şeklinde seslenmek, bütün yabancı insanları çocuğa dayı/dayızade olarak tanıştırmak, otoritesine boyun eğmek ve güven telkin etmek için söylenen, Bilinçdış1 Döneme ait bir söylemdir. Bu ifadenin bilinçdışı algısı, imtiyazlı dayı statüsüdür (Adler, 2000: 122; Ayaz, 2013a: 29; Ayaz, 2015b: 162). İmtiyazlı statü, argo anlam kazanarak dayılanmak, dayılık etmek söylemlerinde de görülür. Söylem, gücüne güvenip diklenmek, day1 gibi davranmak anlamına gelir (Aktunç, 2019: 90). Eylemin harekete geçirici kuvvetini meşrulaştıran, kültürel bellekte onaylanmış dayılık statüsüdür. Dayıyla ilgili çeşitli adlandırmalarda da bu durum görülmektedir.

Uşak Ulubey’in Kışla köyünde, özellikle tarım işçileri ile işveren arasında bağlantıyı, işgücünü ve güvenliği sağlayan kişiye Dayıbaşı denilmektedir. Bu kişi, her şeyden önce güvenilir bir kişi olmalıdır. Çünkü işçiler paralarını almak konusunda tereddüt yaşamamalı, işveren de işinin yapılacağına emin olmalıdır. Bu noktada her iki tarafın da güvendiği ve kefil olduğu kişi olarak dayıbaşı ortaya çıkar. Dayıbaşı, emek-sermaye arasındaki ilişkinin güvencesidir (KK-1). Dayıbaşı kelimesinde kullanılan dayı ifadesi de bilinçdışı dayı hukukundan ileri gelir.

Her ne kadar kültürel yapı dayı aleyhinde dönüşse bile, Türk kültüründe dayıya olan güven, bilinçdışı kolektif bellek içinde devam etmektedir. Bu durum halk anlatılarına da yansımıştır. Dede Korkut Kitabı'nda İç Oğuzla Dış Oğuz’un mücadelesi boyunda dayı statüsünün önemi vurgulanır. Aruz Koca hem beylerbeyi hem de Salur Kazan'ın dayısıdır. Oğuz toplumun bütünlüğünü korumak ve bölünmeleri engellemek adına Salur Kazan dayısını öldürtür. Kamal Abdulla bu olayın, ana soylu yapıyla ilişkili olduğunu ifade eder ve dayının eskiyi sembolize eden güçlü bir statü olduğunu, Salur Kazan'ın dayısını öldürtmesinin eski düzene 
(ana soylu) karşı bir tavır anlamına geldiğini ifade eder (1997: 37). Anlatıda eski yapıyla yeni yapının çatışması, ana soylu yapıdan baba soylu yapıya geçişte yaşanan gerilim görülür. Toplumsal düzen içinde dayının yerini babasının almaya başlamasıyla değişen kabullerin bedelini Beyrek canıyla öder (Ayaz, 2015b: 161). Köroğlu Destanı'nın Özbek rivayetinde ise Köroğlu Bolduruk Kasap'ın evine kılık değiştirip girer ve kendisini Ivaz'ın dayısı olarak tanıtır (Boratav, 1984: 29). Bu sayede güven verir ve eve girebilir.

Türk halk kültürü uygulamalarında da dayı ayrıcalıklı yapısını korur. Örneğin, söz bohçası hazırlanırken gelinin veya damadın aile fertlerinin yanı sıra dayıya da ayrıca bir gömlek vb. hediye konulması gerekmektedir (Ayaz, 2013a: 107). Karakeçeli/Kırıkkale'de damadın dayısı veya amcası gelin alıcı geliyor diye haber vermek için gelin alayından önce kız evine gelir (Koca, 2019: 87). Alaçam Çerkez kültüründe, kız isteme töreninde aile büyüğü olarak dayı veya amca kabul edilir. Dayı veya amca, söz sahibi kimseler olarak görülür (Sevinç, 2019: 68). Nevşehir Derinkuyu'da kız görmeye ilk önce anne, baba, damat, büyükanne ve büyükbaba gider. Eğer kız istenilecekse daha sonra dayı amca gibi büyükler de gider (Çifcibaş, 2018: 75). Bu örneklerin dışında Türk kültüründe pek çok dayı hukukuna istinaden dayıya tanınan ayrıcalık ve statüsüne gösterilen hürmet vardır. Hepsinin temelinde Birinci Bilinçli Dönemin başlangıcından bu güne uzanan dayı hukuku vardır.

\section{Sonuç}

İnsanlığın ilk tarihinden bu güne dayının sahip olduğu statü ve statüsü üzerine inşa edilen hukuk incelenmiştir. Toplumun yaşadığı aile yapısına dayalı kültürel değişmelerin dayı hukuku üzerindeki etkiler, Birinci Bilinçli Söylem Dönemi, İkinci Bilinçli Söylem Dönemi ve Bilinçdışı Söylem Dönemi çerçevesinde değerlendirilmiştir. Birinci dönemde dayının tek başına otorite olduğu ve dayıya ilişkin ifadelerin doğrudan kan bağı olan dayıyı karşıladığ1 görülmüştür. İkinci dönemde ortaya çıkan baba faktörüyle dayının değerinde azalma olmuştur, ancak bu dönem dayı-baba geriliminin yaşandığı bir süreçtir. Dayı, var olan hukukunu korumaya çalışırken, baba ise kendisine toplumu içinde yeni bir rol kazandırmaya çalışmıştır. Bu dönemde dayı-baba geriliminin kalıp ifadelere yansımaları tespit edilmiştir. Üçüncü dönemde ise evliliğin tek geçerli aile yapısı olarak kabul edilmesinden dolayı dayının değerinin oldukça azaldığı görülmüştür. Ancak toplumsallaşmanın yaşandığı ilk andan bu güne dayının kolektif bellek içindeki yerini koruduğu, kalıp ifadelerde dayı kelimesinin bilinçdışı kullanılmasından anlaşılmıştır.

Üç dönem içinde kültürel unsurlara yansıyan dayı, Türk kültüründeki değişim ve dönüşümleriyle incelenmiştir. Toplumun düşünce ve yaşayış şeklini ortaya koyan, aynı zamanda birer hukuk kuralı olarak kabul edilen kalıp ifadeler, anlatılar ve uygulamalar göstermektedir ki bu gün kullanılan dayı kelimesinin ardında kültür tarihi ve halk hukuku vardır. Türk kültüründe dayı, bilinçdışında halâ etkili ve toplumca onaylı bir statü sahibidir. 


\section{Kaynaklar}

Abdulla, K. (1997). Gizli Dede Korkut. A. Duymaz (Çev.). İstanbul: Ötüken.

Adler, A. (2000). Bireysel psikoloji, sosyal roller ve kişilik. T. Yörükân (Çev.), Ankara: Türkiye İş Bankası Kültür.

Aksoy, Ö. A. (2017). Atasözleri ve deyimler sözlüğ̈̈ 1-2. İstanbul: İnkılap.

Aksoy, vd. (2009). Bölge ağızlarında atasözleri ve deyimler I-II. (4.bs.), Ankara: TDK.

Aktunç, H. (2019). Büyük argo sözlüğü (Tanıklarıyla). (12.bs.), İstanbul: Yap1 Kredi.

Assmann, J. (2015). Kültürel bellek. A. Tekin (Çev.), İstanbul: Ayrıntı.

Ayaz, B. (2013a). Balıkesir yöresinde kan bă̆ı ve evlilik dışı akrabalık ilişkileri üzerine bir değerlendirme. Yayımlanmamış Doktora Tezi), Balıkesir: Balıkesir Üniversitesi Sosyal Bilimler Enstitüsü Türk Dili ve Edebiyatı Anabilim Dalı,

Ayaz, B. (2015b). Dede Korkut kitabı bağlamında anaerkil yapıdan ataerkil yapıya geçiş süre c inde avankulat (dayı kültü) kavramı üzerine bir değerlendirme. Uluslararası Türk Dünyası Kültür Araştırmaları Dergisi Bahar 2015 - 1, ss. 155-162.

Bacofen, J. J. (1997). Söylence din ve anaerki. N. Şarman (Çev.), İstanbul: Payel.

Bayat, F. (2016). Ana hatlarıyla Türk şamanlı̆̆

Biçak, a. (2014). Evren tasavvuru kendini bilmek ya da evreni kurmak. İstanbul: Dergah.

Boratav, P. N. (1984). Köroğlu destanı. İstanbul: Adam.

Çakmak, D. (2015). Jinekokrasinin olmadığı anaerkil toplum: Mosuo toplumu. İ.Ü. Siyasal Bilgiler Fakültesi Dergisi No: 52. (Mart 2015). ss.61-83.

Çifcibaş, S. (2018). Nevşehir İli Derinkuyu ilçesi halk kültüründe geçiş dönemleri. (Yayımlanmamış Yüksek Lisans Tezi), Zonguldak: Bülent Ecevit Üniversitesi, Sosyal Bilimler Enstitüsü, Türk Dili ve Edebiyatı Anabilim Dalı.

Çobanoğlu, Ö. (2004). Türk dünyası ortak atasözleri sözlüğü, Ankara: Atatürk Kültür Merkezi Başkanlığ 1 .

Dursun, A. (2015). Türkiye Türkçesi atasözlerinde sözlü hukuk. Uluslararası Sosyal Araştırmalar Dergisi, Haziran, Cilt: 8 Sayı:38, ss.151-160.

Dursun, A. (2016). Türk halk hukuku. Ankara: Ötüken.

Eliade, M. (2015). Doğuş ve yeniden doğuş. F. Aydın (Çev.), İstanbul: Kabalcı.

Geçtan, E. (1998). Psikanaliz ve sonrası. (8.bs.), İstanbul: Remzi.

Güvenç, B. (2002). Insan ve kültür. (9.bs), İstanbul: Remzi.

Halbwachs, M. (2018). Kolektif bellek, Z. Karagöz (Çev.), İstanbul: Pinhan.

İnan, A. (1998). Kazak-Kırgızlar'da yeğenlik hakk1 ve konuk aşı meseleleri, Makaleler ve Incelemeler I. (3.bs.), Ankara: Türk Tarih Kurumu, s.281-291.

İnan, A (1998). Türk dügünlerinde exogamie izleri, Makaleler ve İncelemeler I. (3.bs), Ankara: Türk Tarih Kurumu, s. 341-349,

Jung, G. C. (2017). İnsan ve sembolleri. (2. bs), H. M. İlgün (Çev.), İstanbul: Kabalc1. 
Koca, E. (2019). Türk halk kültüründe damat Muğla'nın Yatağan ilçesi örneği. (Yayımlanmamış Yüksek Lisans Tezi), Muğla: Muğla Sttkı Koçman Üniversitesi, Sosyal Bilimler Enstitüsü, Türk Dili ve Edebiyatı Anabilim Dalı.

Maksudoğlu, M. (1994). İslam ansiklopedisi. Cilt: 9, Türkiye Diyanet Vakfi, s.59-60.

Malinowski, B. (1987). İlkel toplum. H. Portakal (Çev), İstanbul: Öteki.

Malinowski, B. (1992). Vahşilerin cinsel yaşamı. S. Özkal (Çev.), İstanbul: Payel.

Önal, M. N. (2011). Muğla masalları. Muğla: Muğla Üniversitesi.

Özcan, M. T. (1998). İlkel toplumlarda toplumsal kontrol. İstanbul: Özne.

Reed, E. (1982). Kadının evrimi I. Ş. Yeğin (Çev.), İstanbul: Payel.

Sertkaya, O. F. (2018). Kelime dağarcı̆̆ımızdan etimoloji araştırmaları. Ankara: Akçăg.

Sevinç, M. (2019). Alaçam Çerkez halk kültürü. Giresun: (Yayımlanmamış Yüksek Lisans Tezi), Giresun: Giresun Üniversitesi, Sosyal Bilimler Enstitüsü, Türk Dili ve Edebiyatı Anabilim Dalı.

Şenel, A. (1997). Illkel toplumdan uygar topluma. (5.bs.), Ankara: Bilim ve Sanat.

Türkçe Sözlük, (1998). (8.bs.), Ankara: TDK.

\section{Kaynak kişiler}

KK-1 Ömer Ersan, DT: 01.09.1958, Eğt: Orta Okul, Uşak/Ulubey/Kışla Köyü

\section{Elektronik kaynaklar}

Güncel Türkçe sözlük, (e.t. 20.04.2020 https://sozluk.gov.tr/?kelime=i \%C5\%9F\% 20day $\% \mathrm{C} 4 \% \mathrm{~B} 1 \mathrm{ya} \% 20 \mathrm{~d} \% \mathrm{C} 3 \% \mathrm{BC} \% \mathrm{C} 5 \% 9 \mathrm{Ft} \% \mathrm{C} 3 \% \mathrm{BC})$. 